\title{
Renal autoregulation is normal in newly diagnosed, normotensive, NIDDM patients
}

\author{
J.P.New ${ }^{1}$, S.M.Marshall ${ }^{1}$, R.W.Bilous ${ }^{2}$ \\ ${ }^{1}$ Department of Medicine, University of Newcastle upon Tyne, UK \\ ${ }^{2}$ Diabetes Care Centre, Middlesbrough General Hospital, UK
}

\begin{abstract}
Summary Abnormalities of renal autoregulation with glomerular hyperfiltration and raised intraglomerular pressure have been suggested as important factors in the initiation and development of diabetic nephropathy. Angiotensin converting enzyme (ACE) inhibition appears to have a specific reno-protective role in diabetic nephropathy, possibly by reducing intraglomerular pressure. The acute effects of ACE inhibition on renal haemodynamics in normotensive, non-insulin-dependent diabetes mellitus (NIDDM) have not been previously reported. We measured simultaneous glomerular filtration rate (GFR) and renal plasma flow (RPF) in 29 (4 female) subjects, mean age 52 years (range $27-70$ ), using ${ }^{51} \mathrm{Cr}$ EDTA and ${ }^{125}$ I Hippuran. Clearances were corrected to $1.73 \mathrm{~m}^{-2}$. All patients were normotensive (blood pressure $<75^{\text {th }}$ centile for age and sex), newly diagnosed ( $<30$ days), taking no antihypertensive or hypoglycaemic medication. Subjects were randomly allocated (double blind) to receive the ACE inhibitor trandolapril $4 \mathrm{mg}$ day $^{-1}(\mathrm{H})$ (hypotensive dose), trandolapril $0.5 \mathrm{mg} \mathrm{day}^{-1}$ (L) (non-hypotensive dose)
\end{abstract}

or placebo (P) for 10 days after which renal haemodynamics were remeasured. For all subjects baseline GFR, RPF and filtration fraction (FF) were $97 \pm 21 \mathrm{ml} \mathrm{min}^{-1}$ mean $\pm \mathrm{SD}, 439 \pm 120 \mathrm{ml} \mathrm{min}^{-1}$ and $22.3 \pm 2.9 \%$ respectively. Glomerular hyperfiltration $\left(\right.$ GFR $>120 \mathrm{ml} \mathrm{min}^{-1}$ ) was only demonstrated in 3 subjects $(10.3 \%)$. In group $\mathrm{H}$ mean arterial pressure $(103 \pm 8$ vs $93 \pm 9 \mathrm{mmHg}, \quad p<0.001)$ and $\mathrm{FF}$ $(23.8 \pm 2.3$ vs $20.0 \pm 4.0 \%, p=0.03)$ fell while $\mathrm{RPF}$ increased $\left(376 \pm 111\right.$ vs $\left.426 \pm 60 \mathrm{ml} \mathrm{min}{ }^{-1}, p=0.02\right)$, there was no significant change in GFR. No significant change in mean arterial pressure, GFR, RPF or FF occurred in groups $\mathrm{P}$ and $\mathrm{L}$. These studies suggest that in newly diagnosed normotensive NIDDM subjects normal renal autoregulation occurs and glomerular hyperfiltration is uncommon. [Diabetologia (1998) 41: 206-211]

Keywords Renal autoregulation, angiotensin converting enzyme inhibitor, normotension, nephropathy, non-insulin-dependent diabetes mellitus.
Diabetic nephropathy is a major cause of morbidity and mortality in both insulin-dependent diabetes mellitus (IDDM) and non-insulin-dependent diabe-

Received: 2 July 1997 and in revised form: 16 September 1997

Corresponding author: Dr. J. P. New, Department of Endocrinology, Hope Hospital, Stott Lane, Salford M6 8HD, UK Abbreviations: NIDDM, Non-insulin dependent diabetes mellitus; IDDM, insulin-dependent diabetes mellitus; GFR, glomerular filtration rate; RPF renal plasma flow; FF, filtration fraction; AER, albumin excretion rate; MAP, mean arterial blood pressure; ACE, angiotensin converting enzyme. tes mellitus (NIDDM). It is the leading cause of endstage renal failure in the United States and the second most common cause in Europe $[1,2]$. The cumulative incidence of diabetic nephropathy, after 3040 years, is similar in both IDDM and NIDDM (25$45 \%$ ) [3-5]. In the United States NIDDM accounts for $40-90 \%$ of diabetes related renal failure $[6,7]$.

Hypertension accelerates the development of diabetic nephropathy presumably by increasing intraglomerular capillary pressure [8]. Intraglomerular hypertension has been suggested to be an important factor in the development and progression of diabetic glomerulopathy [9]. 
At the onset of experimental diabetes and in newly diagnosed IDDM, abnormalities of renal autoregulation with glomerular hyperfiltration and elevated filtration fraction have been described [9-13]. Animal studies show that these haemodynamic abnormalities are important in the initiation and progression of diabetic glomerulosclerosis [14]. Furthermore commencement of angiotensin converting enzyme (ACE) inhibition at the induction of experimental diabetes normalizes glomerular capillary pressure and prevents diabetic glomerulosclerosis [15].

The aim of the present study was to determine whether newly diagnosed, normotensive, NIDDM patients have normal renal autoregulation, with normal glomerular filtration rate (GFR) and filtration fraction (FF); and whether such autoregulation is influenced by short-term treatment with trandolapril, a long-acting angiotensin converting enzyme inhibitor with high tissue activity.

\section{Patients and methods}

We wrote to local general practitioners, diabetes nurse specialists and the chemical pathology laboratory, who perform oral glucose tolerance tests, asking them to identify newly presenting NIDDM subjects prior to commencing drug treatment or receiving dietary advice. The diagnosis of NIDDM was made using World Health Organization (WHO) criteria [16], in the absence of ketonuria. Suitable subjects were normotensive, blood pressure being under $75^{\text {th }}$ centile for age and sex [17], taking no antihypertensive or hypoglycaemic medication. Exclusion criteria included evidence of renal impairment (serum creatinine $>110 \mu \mathrm{mol} \mathrm{l}^{-1}$, haematuria or dipstick positive proteinuria), urinary tract infection (mid-stream urine culture positive), congestive cardiac failure, abnormalities of liver function tests and drugs known to affect renal function (nonsteroidal anti-inflammatory agents, antihypertensive medication). Three timed overnight urine collections were performed and albumin and urea concentrations were measured by polyethylene glycol radio-immunoassay [18] and by standard automated analysis, respectively. Excretion rates were then calculated. Microalbuminuria was defined as a median urinary albumin excretion rate (AER) of 20-200 $\mu \mathrm{g} \mathrm{min}^{-1}$. During this period patients kept a dietary record from which protein intake was calculated [19]. Following an overnight fast, blood samples were taken for glucose, cholesterol, HDL cholesterol, glycated haemoglobin $\left(\mathrm{HbA}_{1 \mathrm{c}}\right)$, urea and electrolytes. $\mathrm{HbA}_{1 \mathrm{c}}$ was estimated by enzymatic immunoassay (reference range 2.7$4.9 \%$ ) and serum creatinine by a modified Jaffé rate method and serum lipids by standard enzymatic methods (BoehringerMannheim, Lewes, East Sussex, UK) with a Cobas-Bio centrifugal analyzer (Cobas-Bio, Roche Diagnostic Systems, Wel wny Garden City, U.K.).

At 09.00 hours a single intravenous bolus injection of 1 $\mathrm{MBq}$ each of ${ }^{51} \mathrm{Cr}$ EDTA and ${ }^{125}$ I Hippuran (Amersham International, Little Chalfont, Buckinghamshire, UK) was given for the simultaneous estimation of GFR and RPF. These were calculated from the plasma clearance of ${ }^{51} \mathrm{Cr}$ EDTA and ${ }^{125}$ I Hippuran respectively, GFR using a bi-exponential model [20] and RPF using Tauxe's single sample method [21]. FF, an indicator of intraglomerular pressure, was calculated as the ratio of GFR to RPF. Height and weight were recorded from which surface area was calculated. Renal clearances were standardized to $1.73 \mathrm{~m}^{2}$ body surface area. Glomerular hyperfiltration was defined as GFR over $140 \mathrm{ml} \mathrm{min}^{-1} 1.73 \mathrm{~m}^{-2}$ [10] or over $120 \mathrm{ml}$ $\min ^{-1} 1.73 \mathrm{~m}^{-2}[11]$.

After a 5 min rest the supine blood pressure was measured in triplicate, to the nearest $2 \mathrm{mmHg}$, using a standard sphygmomanometer with the appropriate sized cuff and the mean arterial blood pressure (MAP) (diastolic blood pressure $+[$ [systolic blood pressure-diastolic blood pressure $\quad \div 3$ ]) calculated. Fundoscopy was performed after mydriasis.

After completing these basal investigations the patients were randomized, in a double blind manner, to receive placebo (P), trandolapril $0.5 \mathrm{mg}$ once daily (L) or trandolapril $4 \mathrm{mg}$ daily $(\mathrm{H})$. Trandolapril $4 \mathrm{mg} \mathrm{day}^{-1}$ causes systemic hypotension whereas $0.5 \mathrm{mg} \mathrm{day}^{-1}$ does not reduce systemic blood pressure but may affect renal haemodynamics [22]. After 10 days' treatment the renal clearances and metabolic parameters were remeasured. All patients completed the study and all observations were made by one person (J.N.).

Fully informed written consent was obtained from each subject and the study was approved by the local Health $\mathrm{Au}-$ thority ethics committees.

Statistical analysis. Statistical evaluation was performed using the statistical software SPSS for Windows (SPSS Inc, Chicago, Ill., USA). Comparisons were made on an intention to treat basis. Continuous variables were analysed by analysis of variance (ANOVA). As age differed between the groups it was included as a co-variant in the ANOVA model. All pairwise comparisons were subject to the Bonferroni correction for multiple comparisons. All results are expressed as mean \pm SD except for urinary AER (geometric mean and range) which was not normally distributed.

\section{Results}

The baseline renal haemodynamic data for all subjects and the three individual groups are shown in Table 1. Initial investigations confirmed the diagnosis of diabetes, random blood glucose $13.4 \pm$ $5.3 \mathrm{mmol} \mathrm{l}^{-1}$ and $\mathrm{HbA}_{1 \mathrm{c}} 7.9 \pm 2.1 \%$. One patient refused to undergo fundoscopy, two subjects had background diabetic retinopathy and the remainder had normal fundoscopy. Four (14\%) subjects had microalbuminuria, two of whom had background retinopathy.

Glomerular hyperfiltration, defined as GFR over $140 \mathrm{ml} \mathrm{min}^{-1} 1.73 \mathrm{~m}^{-2}$ or over $120 \mathrm{ml} \mathrm{min}{ }^{-1} 1.73 \mathrm{~m}^{-2}$, occurred in $1(3.4 \%)$ and $3(10.3 \%)$ subjects, respectively. There was no difference in protein intake or urinary urea excretion in the hyperfiltering subjects compared to the remaining subjects. There were no differences in any metabolic or renal parameters between the normoalbuminuric $(n=25)$ and microalbuminuric $(n=4)$ subjects.

GFR was significantly correlated with RPF $(\mathrm{GFR}=0.16 \mathrm{RPF}+27, r=0.85 . p<0.0001)$; and inversely with age $(\mathrm{GFR}=143-0.9$ age, $r=-0.48$, $p=0.0009$ ) (Fig.1). No significant correlation was demonstrated between GFR and AER, fasting glu- 
Table 1. Baseline clinical and renal data of the newly diagnosed, untreated, normotensive NIDDM subjects

\begin{tabular}{|c|c|c|c|c|c|}
\hline Group & All subjects & Placebo & $\begin{array}{l}\text { Trandolapril } \\
\left(0.5 \mathrm{mg} \cdot \text { day }^{-1}\right)\end{array}$ & $\begin{array}{l}\text { Trandolapril } \\
\left(4 \mathrm{mg} \cdot \text { day }^{-1}\right)\end{array}$ & ANOVA \\
\hline Number (female) & $29(4)$ & $10(1)$ & $8(1)$ & $11(2)$ & NS \\
\hline $\operatorname{BMI}\left(\mathrm{kg} \mathrm{m}^{-2}\right)$ & $30.1 \pm 4.2$ & $31.1 \pm 4.4$ & $30.1 \pm 4.9$ & $29.2 \pm 3.6$ & NS \\
\hline MAP $(\mathrm{mm} \mathrm{Hg})$ & $97 \pm 9$ & $93 \pm 9$ & $94 \pm 10$ & $103 \pm 8^{a}$ & 0.04 \\
\hline Glucose $\left(\mathrm{mmol} \mathrm{l}^{-1}\right)$ & $13.4 \pm 5.3$ & $15.1 \pm 4.1$ & $12.0 \pm 4.9$ & $12.8 \pm 6.7$ & NS \\
\hline $\mathrm{HbA}_{1 \mathrm{c}}$ (\% normal range, 2.7-4.9) & $7.9 \pm 2.1$ & $8.6 \pm 1.9$ & $6.9 \pm 2.2$ & $8.1 \pm 1.8$ & NS \\
\hline $\mathrm{FF}(\%)$ & $22.3 \pm 2.9$ & $21.6 \pm 2.9$ & $21.6 \pm 3.9$ & $23.8 \pm 2.3$ & NS \\
\hline $\operatorname{AER}\left(\mu \mathrm{g} \mathrm{min} \min ^{-1}\right)$ & $5.3(1.5-120)$ & $11.0(4.7-120)$ & $4.2(2.3-9.7)$ & $6.1(1.5-34.5)$ & NS \\
\hline Urinary urea $\left(\mathrm{mmol} \mathrm{l}^{-1}\right)$ & $319 \pm 131$ & $361 \pm 121$ & $281 \pm 136$ & $302 \pm 125$ & NS \\
\hline Protein intake $\left(\mathrm{g} \mathrm{day}^{-1}\right)$ & $97 \pm 26$ & $84 \pm 24$ & $92 \pm 21$ & $112 \pm 26$ & NS \\
\hline
\end{tabular}

Data is shown for all patients and for the three treatment groups. Comparisons shown relate to the three treatment groups.

a Trandolapril $4.0 \mathrm{mg}$ compared to placebo and trandolapril $0.5 \mathrm{mg}$. Bonferroni $p<0.05$.
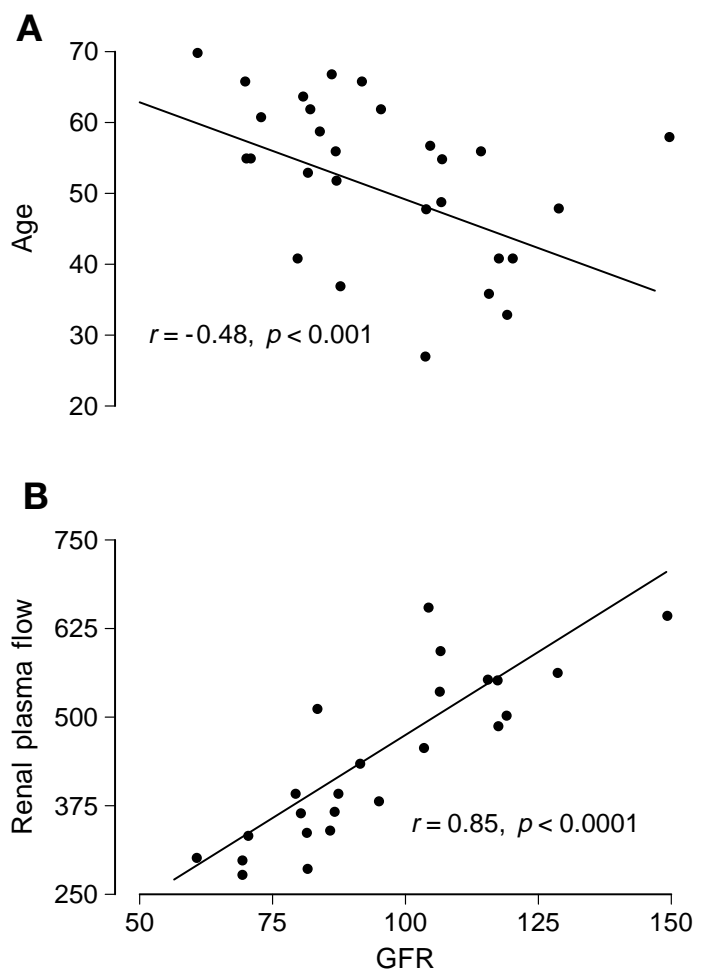

Fig.1(A, B). Correlation of glomerular filtration rate (GFR) with age (A) and renal plasma flow $(\mathbf{B})$ in normotensive, newly diagnosed NIDDM patients. Renal clearances, expressed as $\mathrm{ml}$ $\mathrm{min}^{-1}$, were standardized to $1.73 \mathrm{~m}^{2}$ body surface area

cose, $\mathrm{HbA}_{1 \mathrm{c}}$, glycosuria, protein intake and systolic or diastolic blood pressure.

Subjects randomly allocated to group $\mathrm{H}$ were significantly older than group $\mathrm{P}$ with a significantly higher MAP than groups L and P (Table 1). All remaining baseline variables were similar within the groups.

During the study glycaemic control (assessed by random plasma glucose or glycated haemoglobin)
Data are expressed as mean \pm SD except for albumin excretion rate (AER) which is geometric mean and range.

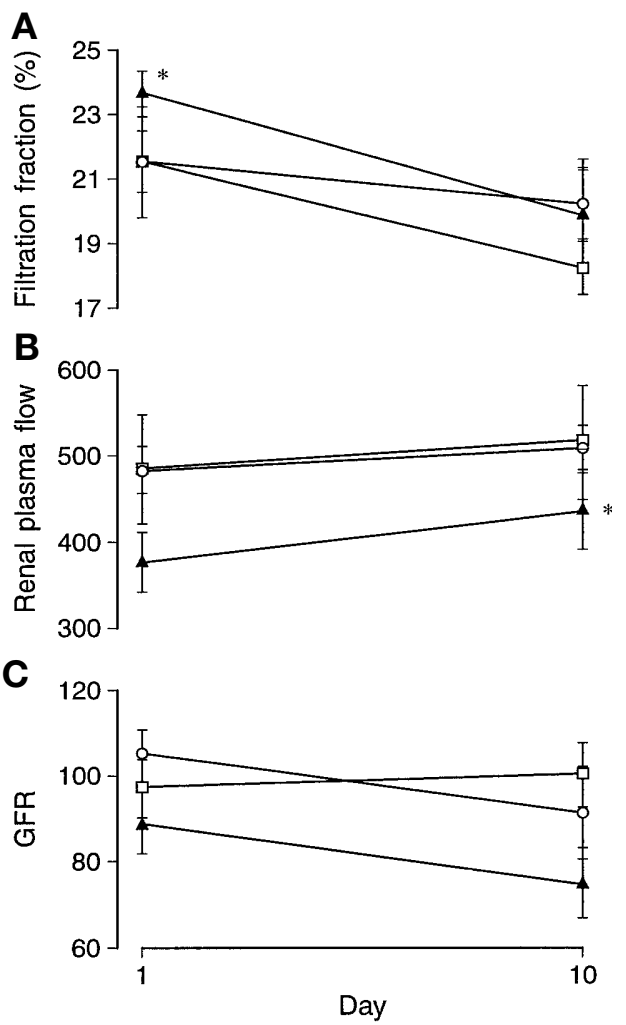

Fig. 2(A-C). Effects of 10 days' treatment with trandolapril $4 \mathrm{mg} \mathrm{day}^{-1}(\boldsymbol{\Delta})$, trandolapril $0.5 \mathrm{mg} \mathrm{day}^{-1}(\square)$ or placebo $(\bigcirc)$ on filtration fraction (FF) (A); renal plasma flow (RPF) (B); and glomerular filtration rate (GFR) $(\mathbf{C})$. GFR and RPF are expressed as $\mathrm{ml} \mathrm{min}{ }^{-1}$, and were standardized to $1.73 \mathrm{~m}^{2}$ body surface area. ${ }^{*} p<0.05$ day 1 compared to day 10

and protein intake (urinary urea excretion and calculated protein intake) did not change and were similar in the three groups. MAP was reduced in group $\mathrm{H}$ $(103 \pm 8$ vs $93 \pm 9 \mathrm{mmHg}, p<0.001)$, but was unchanged in groups $\mathrm{P}$ and $\mathrm{L}$. The effects of treatment 
were compared using an ANOVA model with age as a covariant.

In group $\mathrm{H}, \mathrm{FF}$ was reduced $(23.8 \pm 2.3$ vs $20.0 \pm 4.0, p=0.03$ ) and RPF increased (376 vs

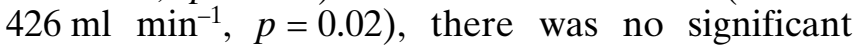
change in GFR. In groups $\mathrm{P}$ and $\mathrm{L}$ no significant changes in GFR, RPF or FF were observed (Fig. 2). AER was not altered by treatment with high or low dose trandolapril or placebo.

Of the four subjects with microalbuminuria only one had a GFR over $120 \mathrm{ml} \mathrm{min}^{-1} 1.73 \mathrm{~m}^{-2}$. In the one microalbuminuric subject treated with trandolapril (H), AER fell to within the normoalbuminuric range. The remaining three patients with initial microalbuminuria were randomised to the placebo group and all remained microalbuminuric.

\section{Discussion}

This randomised, controlled, double blind study demonstrates the neutral effect of using the ACE inhibitor trandolapril, at hypotensive and non-hypotensive doses, on renal haemodynamics in newly diagnosed, normotensive NIDDM patients. The results suggest that renal autoregulation is preserved, maintaining GFR and RPF despite pharmacologically induced changes in systemic blood pressure, and that glomerular hyperfiltration is relatively uncommon in these patients. Too few patients had microalbuminuria for specific comment upon the effect of ACE inhibition.

Renal autoregulation ensures that RPF and GFR remain relatively constant despite wide variations in arterial blood pressure [23]. This phenomenon occurs in innervated, denervated and isolated kidneys [24] and is therefore believed to be mediated by mechanisms intrinsic to the kidney. GFR is determined by $\mathrm{RPF}$, itself determined by the balance between afferent and efferent renal arteriolar resistance, transglomerular pressure gradient, the difference between mean hydrostatic pressure and oncotic pressure, and the ultra filtration coefficient which is determined by glomerular permeability and the filtration surface area [25]. In group $\mathrm{H}$, despite a reduction in systemic blood pressure, there was no associated reduction in GFR or RPF. Indeed there was an increase in RPF and a reduction in FF suggesting a proportionally greater reduction in efferent (than afferent) glomerular arteriolar resistance with a reduction in intraglomerular pressure. The baseline GFR and RPF where lower in the patients receiving trandolapril $4 \mathrm{mg}(\mathrm{H})$. This difference was not statistically significant however, and is probably age-related as group $\mathrm{H}$ patients were older [26].

In experimental diabetes single nephron and whole kidney GFR, RPF and intraglomerular pressure are increased soon after the onset of hyperglycaemia, while systemic blood pressure remains nor- mal [14]. Intraglomerular hyperfiltration and hypertension lead to glomerular sclerosis in the absence of systemic hypertension [27]. These haemodynamic changes suggest that renal autoregulation is abnormal from the very early stages of experimental diabetes and imply that corrective mechanisms of glomerular damage are different from man. These contrasts may partly explain the different pathology observed in kidneys from diabetic rats and human subjects.

Glomerular hyperfiltration, defined as GFR over $140 \mathrm{ml} \mathrm{min}{ }^{-1} 1.73 \mathrm{~m}^{-2}$ [10] or over $120 \mathrm{ml} \mathrm{m^{-1 }}$ $1.73 \mathrm{~m}^{-2}$ [11], was uncommon in this study. As it is difficult to assess the duration of NIDDM prior to diagnosis it is not possible to be sure that glomerular hyperfiltration had not occurred previously, with normalisation prior to the diagnosis. However, we studied otherwise healthy patients who were newly diagnosed so as to obtain the shortest possible known duration of disease. Vora et al. [11], using identical methodology, had previously established a mean \pm SD GFR of $95 \pm 12 \mathrm{ml} \mathrm{min}^{-1} 1.73 \mathrm{~m}^{-2}$ and RPF of $472 \pm 70 \mathrm{ml} \mathrm{min}^{-1} 1.73 \mathrm{~m}^{-2}$ in non-diabetic subjects of a similar age to the subjects we studied [11]. Our definitions of hyperfiltration were partly based on their data.

Our results are similar to Schmitz et al. $[12,13]$ but contrast with those of others [11, 28, 29]. Schmitz and colleagues [12] measured GFR in 10 newly diagnosed untreated NIDDM subjects comparable to ours for age, degree of hyperglycaemia and blood pressure. Their mean GFR was $106 \pm 14.6 \mathrm{ml} \mathrm{min}^{-1} 1.73 \mathrm{~m}^{-2}$,

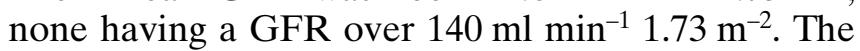
same group also measured GFR in 18 , normoalbuminuric, NIDDM patients with a known diabetes duration of 5 years (D) and control subjects (C) [13]. Mean GFRs were similar; $100.4 \pm 16.7$ (D) and $93.8 \pm 11.4(\mathrm{C}) \mathrm{ml} \mathrm{min}^{-1} 1.73 \mathrm{~m}^{-2}(p=\mathrm{NS})$. Vora and colleagues [11] studied a group of 110 newly diagnosed, untreated and normotensive NIDDM subjects. They found GFR over $140 \mathrm{ml} \mathrm{min}^{-1} 1.73 \mathrm{~m}^{-2}$ and GFR over $120 \mathrm{ml} \mathrm{min}^{-1} 1.73 \mathrm{~m}^{-2}$ in $16 \%$ and $45 \%$ of subjects, respectively. The reason for the increased prevalence of glomerular hyperfiltration compared with our results is unclear. Age, blood pressure, glycaemic control and race were similar in both studies. However, even their results suggest that hyperfiltration is less common in newly diagnosed NIDDM compared to IDDM subjects [10,30]. Palmisano and Lebovitz [29] studied 72 black American NIDDM patients, 18 within 1 year of diagnosis. All were treated with sulphonylureas or insulin (fasting plasma glucose $6.7 \mathrm{mmol} \mathrm{l}^{-1}$ ), were normotensive $(127 / 83 \mathrm{mmHg})$ and had a mean age of 48 years. Glomerular hyperfiltration ( $>140 \mathrm{ml} \mathrm{min}^{-1} 1.73 \mathrm{~m}^{-2}$ ) was demonstrated in 7 of the $18(39 \%)$ subjects. Of the 60 subjects studied within the first 10 years of diagnosis 15 (25\%) had a GFR above this level. Nowack et al. [28] studied 16 subjects within 10 months 
of diagnosis of NIDDM. GFR was measured in this group and two non-diabetic control groups, nonobese normotensive and obese normotensive. In the diabetic group GFR was over $95^{\text {th }}$ percentile of the normal range established in the non-obese group in $44 \%$ and over $95^{\text {th }}$ percentile of the normal range established in the obese group in $50 \%$ of subjects.

Studies in the Pima Indians, who have regular glucose tolerance tests at 2 yearly intervals, provide a unique opportunity to evaluate GFR in NIDDM patients of known disease duration. Myers et al. [31] measured GFR and RPF in two groups, one non-diabetic and another within 2 years of developing NIDDM. While the uncorrected GFR was significantly higher in the diabetic patients compared to control subjects (140 vs $\left.122 \mathrm{ml} \mathrm{m^{-1 }} 1.73 \mathrm{~m}^{-2}, p=0.01\right)$ this difference was lost after correcting GFR for body surface area (119 vs $\left.110 \mathrm{ml} \mathrm{min}^{-1} 1.73 \mathrm{~m}^{-2}, p=0.20\right)$. Myers et al. concluded that true glomerular hyperfiltration is present in these recent onset NIDDM Pima Indians because the correction for body surface area is biased by obesity. However, Nowack et al. [28] corrected GFR for surface area and lean body mass by using densitometry (weighing the subjects under water). They found that GFR corrected for lean body mass differed by only $5 \%$ from the value derived from standard body surface area. Thus Myers et als. data in newly diagnosed Pima Indians could equally be interpreted as showing no hyperfiltration. More recent data from the same group has demonstrated glomerular hyperfiltration in the newly diagnosed and microalbuminuric NIDDM Pima Indians [32]. Interestingly in those progressing from impaired glucose tolerance to overt diabetes GFR increased by $35 \%$. However initial GFR did not predict worsening albuminuria and microalbuminuric NIDDM patients had stable GFR over the 4-year follow up period. Data were not corrected for body surface area because of obesity. It is interesting to note however that the newly diagnosed diabetic subjects were considerably heavier than the normal glucose tolerance control subjects. Thus, corrected GFR may not have been significantly different between the two groups.

Infusions of both glucose and ketone bodies have been shown to raise GFR acutely in IDDM [33, 34] and may account for the increased prevalence of hyperfiltration in newly diagnosed IDDM patients, [35, 36]. None of our patients were ketonuric. High protein intake may increase GFR. Our dietary protein estimates and urinary urea excretion do not suggest that the patients were on a particularly low protein diet.

Both GFR and RPF were maintained despite treatment with ACE inhibitors which reduced systemic MAP at the higher dose $(\mathrm{H})$ suggesting that renal autoregulation is preserved in the early stages of NIDDM. Similar results have been observed in IDDM subjects without nephropathy whereas abnormal autoregulation was demonstrated in IDDM sub- jects with nephropathy [37]. Within the nephropathic group a wide variation in response of GFR to acute blood pressure reduction occurred ranging from normal to severely impaired autoregulation. The authors suggested that the impaired autoregulation could involve either structural changes (arteriolar hyalinosis) and/or functional disturbances of smooth muscle reactivity. The nephropathic group all demonstrated arterial hyalinosis on their renal biopsy.

In human diabetes glomerular hyperfiltration, possibly secondary to intraglomerular hypertension, has been suggested as a predisposing risk factor for the subsequent development of diabetic nephropathy $[8$, $38,39]$ although the evidence is conflicting [36, 40]. Rudberg et al. [39] demonstrated that glomerular hyperfiltration (GFR $>125 \mathrm{ml} \mathrm{min}^{-1} 1.73 \mathrm{~m}^{-2}$ ) was an independent predictor for the subsequent ( 8 years) development of combined microalbuminuria and nephropathy. Only $50 \%$ of the hyperfiltering group developed nephropathy implying that glomerular hyperfiltration alone was insufficient to cause nephropathy. Other investigators $[36,40]$ failed to confirm this association. Similar follow-up studies to examine the possible role of hyperfiltration in NIDDM are required.

Drummond et al. [41] studied the effects of 4 weeks' ACE inhibition on renal function in 18 normotensive, normoalbuminuric, hyperfiltering IDDM children. Despite suppressing ACE activity and MAP there was no change in GFR, RPF or FF. Thus, even in subjects with glomerular hyperfiltration, autoregulation is preserved. They concluded that the renin angiotensin system was not involved in the glomerular hyperfiltration seen in IDDM and they could show no evidence for the presence of intraglomerular hypertension in their patients. Our data would support this conclusion in NIDDM patients.

Although the results of this study should be interpreted carefully, in view of the relatively small numbers of subjects studied, our findings of normal renal autoregulation and a low prevalence of glomerular hyperfiltration in newly diagnosed, normotensive NIDDM perhaps casts doubt on the primary role of abnormal renal haemodynamics in the development of diabetic nephropathy in such patients. Short-term use of ACE inhibitors had no adverse effects on renal function in uncomplicated NIDDM subjects.

Acknowledgements. This study was supported by Hoechst Marion Roussel. We would like to thank Mr. D. Rodham and Dr. M. Keir for their technical assistance in measuring GFR and RPF.

\section{References}

1. Raine AEG (1993) The EDTA Registry: epidemiology, development and treatment of end stage renal failure in non insulin dependent diabetics in Europe. Diabetologia 36: 1099-1104 
2. United States renal data service (1990) Annual data report 1990. Am J Kidney Dis [Suppl 2] 16-27

3. Ballard DJ, Humphrey LL, Melton J et al. (1988) Epidemiology of persistent proteinuria in type 2 diabetes mellitus. Population based study in Rochester, Minnesota. Diabetes 37: 405-412

4. Hasslacher C, Ritz E, Wahl P, Michael C (1989) Similar risks of nephropathy in patients with type 1 or type II diabetes mellitus. Nephrol Dial Transplant 4: 859-863

5. Ritz E, Keller CK, Bergis KH, Siebels M (1994) Renal involvement in type II diabetes. Clin Nephrol 3: 137-144

6. Rettig B, Teusch S (1984) The incidence of end-stage renal disease in type I and type II diabetes mellitus. Diabetic Nephropathy 3: 26-27

7. Cowie CC, Port FK, Wolfe RA et al. (1989) Disparities in incidence of diabetic end stage renal disease according to race and type of diabetes. N Engl J Med 321: 1074-1079

8. Parving HH, Viberti GC, Keen H, Christiansen JS, Lassen NA (1983) Haemodynamic factors in the genesis of diabetic microangiopathy. Metabolism 32: 943-949

9. Hostetter TH, Rennke HG, Brenner BM (1982) The case for intrarenal hypertension in the initiation and progression of diabetic and other glomerulopathies. Am J Med 72: $375-380$

10. Mogensen CE (1971) Kidney function and glomerular permeability to macromolecules in early juvenile diabetes. Scand J Clin Lab Invest 28: 79-90

11. Vora JP, Dolben J, Dean JD, et al. (1992) Renal haemodynamics in newly presenting non-insulin-dependent diabetes mellitus. Kidney Int 41: 829-835

12. Schmitz A, Hvid Hansen H, Christensen T (1989) Kidney function in newly diagnosed type 2 (non-insulin-dependent) diabetic patients, before and during treatment. Diabetologia 32: 434-439

13. Schmitz A, Christensen T, Taagehoej Jensen F (1989) Glomerular filtration rate and kidney volume in normoalbuminuric non-insulin dependent diabetes - lack of glomerular hyperfiltration and renal hypertrophy in uncomplicated NIDDM. Scand J Clin Lab Invest 48: 103-108

14. Zatz R, Meyer T, Rennke H, Brenner BM (1985) Predominance of haemodynamic rather than metabolic factors in the pathogenesis of diabetic glomerulopathy. Proc Natl Acad Sci (USA) 82: 5963-5967

15. Zatz R, Dunn R, Meyer T, Anderson S, Rennke H, Brenner BM (1986) Prevention of diabetic glomerulopathy by pharmacological amelioration of glomerular capillary hypertension. J Clin Invest 77: 1925-1930

16. World Health Organisation (1985) Diabetes mellitus. Report of a WHO Study Group. Technical Report Series No 727, World Health Organization, Geneva

17. Acheson R (1973) Blood pressure in a national sample of US adults: percentile distribution by age, sex and race. Int J Epidemiology 2: 293-301

18. Christensen CM, Orskov C (1984) Rapid screening PEG radioimmunoassay for quantification of pathological microalbuminuria. Diabetic Nephropathy 3: 92-97

19. Bassham S, Fletcher LR, Stanton RJH (1984) Dietary analysis with the aid of a microcomputer. J Microcomp Applic 7: 279-289

20. Vora JP, Burch A, Owens DR, Peters JR (1991) Simultaneous determination of glomerular filtration rate and effective renal plasma flow. Clin Physics Physiol Measurement 12: $269-277$

21. Tauxe WN, Dubovsky EV, Kidd TE (1984) Comparison of measurement of effective renal plasma flow by single plasma sample and plasma disappearance slope/volume methods. Eur J Nucl Med 9: 443-445
22. Gaillard CA, de Leeuw PW (1993) Clinical experiences with trandolapril. Am Heart J 25: 1536-1541

23. Shipley RE, Study RS (1951) Changes in renal blood flow, extraction of inulin, glomerular filtration rate, tissue pressure and urine flow with acute alteration of renal artery blood pressure. Am J Physiol 167: 676-688

24. Brenner BM, Zatz R, Ichikawa I (1986) The renal circulations. In: Brenner BM, Rector FC (eds) The kidney (third edition). WB Saunders, Philadelphia, pp 93-123

25. Brenner BM, Dworkin LD, Ichikawa I (1986) Glomerular filtration. In: Brenner BM, Rector FC (eds) The kidney (third edition). WB Saunders, Philadelphia, pp 124-145

26. Rowe JW, Andres R, Tobin JD, Norris AH, Shock NW (1976) Age-adjusted standards for creatinine clearance. Anns Int Med 84: 567-570

27. Zatz R, Brenner BM (1986) Pathogenesis of diabetic microangiopathy. The haemodynamic view. Am J Med 80: 443-453

28. Nowack R, Raum E, Blum W, Ritz E (1992) Renal haemodynamics in recent-onset type II diabetes. Am J Kidney Dis 10: 342-347

29. Palmisano JJ, Lebovitz HE (1989) Renal function in black Americans with type II diabetes. J Diabetic Complications 3: 40-44

30. Mogensen CE, Andersen MJF (1973) Increased kidney size and glomerular filtration rate in early juvenile diabetes. Diabetes 22: 706-713

31. Myers BD, Nelson RG, Williams GW et al. (1991) Glomerular function in Pima Indians with non-insulin-dependent diabetes mellitus of recent onset. J Clin Invest 88: 524-530

32. Nelson RG, Bennett PH, Beck GJ et al. (1996) Development and progression of renal disease in Pima Indians with non-insulin dependent diabetes mellitus. NEJM 335: 1636-1642

33. Nosadini R, Trevisan R, Fioretto P et al. (1989) Kidney haemodynamics after ketone body and amino acid infusion in normal and IDDM subjects. Diabetes 38: 75-83

34. Skott P, Vaag A, Holter-Nielson O et al. (1991) Effects of hyperglycaemia on kidney function, atrial naturetic factor and plasma renin in patients with insulin-dependent diabetes mellitus. Scand J Clin Lab Invest 51: 715-727

35. Christiansen JS, Gammelgaard J, Frandsen M, Parving HH (1981) Increased kidney size, glomerular filtration rate and renal plasma flow in short-term insulin dependent diabetics. Diabetologia 20: 451-456

36. Lervang HH, Jensen S, Brøcher-Mortensen J, Ditzel J (1988) Early glomerular hyperfiltration and the development of late nephropathy in type 1 (insulin dependent) diabetes mellitus. Diabetologia 31: 723-729

37. Parving H-H, Kastrup H, Smidt UM et al. (1984) Impaired autoregulation of glomerular filtration rate in type 1 (insulin-dependent) diabetic patients with nephropathy. Diabetologia 27: 547-552

38. Mogensen CE (1986) Early glomerular hyperfiltration in insulin-dependent diabetes and late nephropathy. Scand J Clin Lab Invest 46: 201-206

39. Rudberg S, Persson B, Dahlquist (1992) Increased glomerular filtration rate as a predictor of diabetic nephropathy An 8-year prospective study. Kidney Int 41: 822-828

40. Yip JW, Jones SL, Wiseman MJ, Hill C, Viberti GC (1996) Glomerular hyperfiltration in the prediction of nephropathy in IDDM: a 10 year follow up study. Diabetes 45: 1729-1733

41. Drummond K, Levy-Marchal C, Laborde K et al. (1989) Enalapril does not alter renal function in normotensive, normoalbuminuric, hyperfiltering type 1 (insulin-dependent) diabetic children. Diabetologia 32: 255-260 